\title{
Genetic Divergence for the Amphibian Pleurodeles walt in Southwest Portugal: Dispersal Barriers Shaping Geographic Patterns
}

Author(s): Mirjam S. van de Vliet, Onno E. Diekmann, Margarida Machado, Trevor J. C. Beebee, Pedro Beja, and Ester A. Serrão

Source: Journal of Herpetology, 48(1):38-44. 2014.

Published By: The Society for the Study of Amphibians and Reptiles

DOI: http://dx.doi.org/10.1670/12-181

URL: http://www.bioone.org/doi/full/10.1670/12-181

BioOne (www.bioone.org) is a nonprofit, online aggregation of core research in the biological, ecological, and environmental sciences. BioOne provides a sustainable online platform for over 170 journals and books published by nonprofit societies, associations, museums, institutions, and presses.

Your use of this PDF, the BioOne Web site, and all posted and associated content indicates your acceptance of BioOne's Terms of Use, available at www.bioone.org/page/terms_of_use.

Usage of BioOne content is strictly limited to personal, educational, and non-commercial use. Commercial inquiries or rights and permissions requests should be directed to the individual publisher as copyright holder. 


\title{
Genetic Divergence for the Amphibian Pleurodeles waltl in Southwest Portugal: Dispersal Barriers Shaping Geographic Patterns
}

\author{
Mirjam S. van de Vliet,${ }^{1,2,3}$ Onno E. Diekmann, ${ }^{1}$ Margarida Machado,${ }^{1}$ Trevor J. C. Beebee,${ }^{4}$ Pedro Beja, ${ }^{2}$ \\ AND ESTER A. SERRÃO ${ }^{1}$ \\ ${ }^{1}$ CCMAR-CIMAR, F.C.M.A-University of Algarve, Gambelas, P-8005-139 Faro, Portugal \\ ${ }^{2}$ EDP Biodiversity Chair, CIBIO-Centro de Investigação em Biodiversidade e Recursos Genéticos, Universidade do Porto, Campus Agrário de Vairão, \\ 4485-66 Vairão, Portugal \\ ${ }^{4}$ Biochemistry Department, School of Life Sciences, University of Sussex, Falmer, Brighton BN1 9QG, United Kingdom
}

\begin{abstract}
Dispersal and vicariance are the principal mechanisms responsible for the formation of biogeographic patterns, driven or maintained by the role of past and current barriers to dispersal. Southwest Portugal harbors a rich endemic fauna and flora where strongly differentiated taxa can be observed, suggesting ancient isolating mechanisms acted in this region. In this study, we used information from two partial mitochondrial sequences, combined with information from microsatellite loci and amplification success, to investigate biogeographic patterns of genetic divergence in populations of Pleurodeles waltl in Portugal. Our results demonstrate genetic differentiation at different time frames creating distinct populations in southwest Portugal, which might have arisen following isolation by a large river estuary and mountainous barriers. Habitat destruction associated with agricultural intensification raises conservation concerns over the unique biodiversity in this region.
\end{abstract}

The Mediterranean region, including the Iberian Peninsula, is an important biodiversity hotspot with high levels of endemism and diversity (Blondel et al., 2010), and it was an important Pleistocene glacial refugium for a wide spectrum of taxa attributable to geographical and topographical heterogeneity (Gómez and Lunt, 2007). These geographical constraints created coincident distribution patterns for several taxonomic groups (Avise, 2000; Hewitt, 2000, 2004). Southwest Iberia is geographically restricted, with barriers to dispersal maintained by rivers and mountain ranges. This restriction sustains divergent phylogenetic lineages of plants (Comes and Abbot, 1998), aquatic invertebrates (Korn et al., 2010), fish (Almada and Sousa-Santos, 2010), amphibians (e.g, Steinfartz et al., 2000; Martínez-Solano et al., 2006; Gonçalves et al., 2009), reptiles (e.g., Guicking et al., 2002; Miraldo et al., 2011), and others (reviewed in Gómez and Lunt, 2007; Schmitt, 2007). Therefore, studies in this region focusing on dispersal patterns and phylogeography are of interest. In addition, the conservation status of these vicariant lineages may be of great concern because of their restricted ranges, particularly in the case of species confined to small areas of critical habitat like temporary ponds (Beja and Alcazar, 2003; Cancela da Fonseca et al., 2008). The conservation of these unique communities deserves priority as part of the conservation of European biodiversity (Stoate et al., 2009). This situation prompted the development of genetic markers for temporary pond amphibians to understand population connectivity patterns in this geographically restricted region (van de Vliet et al., 2009a,b,c).

Urodele amphibians are known to have more limited dispersal capabilities than anurans (Smith and Green, 2005), often creating genetically structured populations over relatively short geographical distances, while retaining signals of historical events that generated current species distributions (Zeisset and Beebee, 2008). The Sharp-Ribbed Salamander or Spanish Newt (Pleurodeles waltl) is an urodele species found in Spain, Portugal, and Morocco. In Portugal, it is found throughout the country, although restricted to warm, nonmountainous areas, resulting in highest abundance toward the south (Gasc, 1997;

${ }^{3}$ Corresponding Author. E-mail: mvliet@ualg.pt

DOI: $10.1670 / 12-181$
Loureiro et al., 2010). A preliminary study of population genetics employing microsatellite analyses revealed increased amplification failure across a likely barrier to movement, indicating possible genetic divergence within a relatively small area. In addition, Carranza and Arnold (2004) indicated the existence of two lineages in the southern part of Iberia, including one location in Portugal. Information from nuclear microsatellites in combination with sequences from mitochondrial DNA markers can be useful for understanding past and contemporary processes affecting spatial distribution of genetic diversity. Although mtDNA can reconstruct ancestral population events, microsatellites are more useful for explaining patterns at a finer scale in more recent time frames (Zeisset and Beebee, 2008). Amplification success or failure of microsatellite loci related to mutations in the primer annealing sites can be employed as an extra signal of phylogenetic divergence (Hendrix et al., 2010).

In this study, we used the combination of two mtDNA sequences and information from nuclear microsatellites to infer genetic discontinuities in populations of $P$. walt in Portugal. In particular, we aimed to assess the hypothesis that physical barriers could explain geographic patterns of genetic divergence and differentiation in southwest Portugal.

\section{Materials AND Methods}

Pleurodeles walt individuals were sampled from each of 19 breeding sites (Fig.1 and Table S1, which is available online at: http:/ /dx.doi.org/10.1670/12-181s1) along the species range in Portugal. Breeding sites in southwest Portugal (Parque Natural do Sudoeste Alentejano e Costa Vicentina) have been surveyed in detail for several species (Beja and Alcazar, 2003; P. Beja, unpubl. data) and are clustered in seven main regional networks, separated by presumably unfavorable habitat for amphibian dispersal (e.g., stream valleys, Rio Mira estuary and several mountainous areas (e.g., Serra do Caldeirão, Serra de Monchique). The regions are Vila Nova de Milfontes (VNM), Almograve (Alm), Cavaleiro (Ca), Zambujeira (Za), Brejão ( $\mathrm{Br})$, Aljezur (Alj), and Vila do Bispo (VdB) (Fig. 1 enlarged).

Tail clips from larvae (Alm, 100 individuals from seven breeding sites; VNM, 41 individuals from eight breeding sites) 


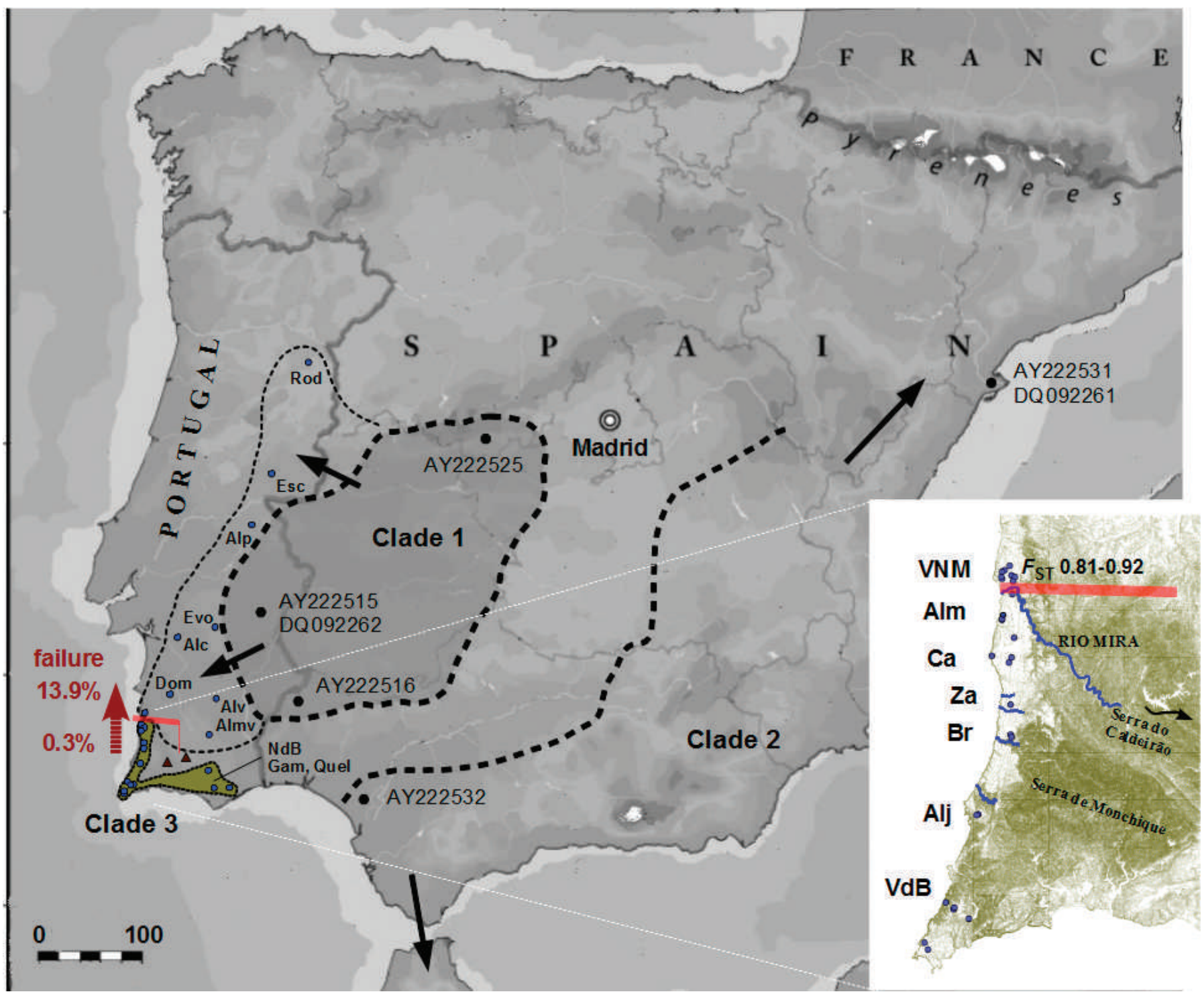

FIG 1. Distribution of individuals of Pleurodeles waltl in the Iberian Peninsula sampled for mitochondrial analyses. Clades in Spain are redrawn from Carranza and Arnold (2004) where black arrows illustrate the presence of clade one in an expanded region (according to our results) from central Spain covering a large part of Portugal and clade two covering East Spain. Locations of published haplotype samples (AY-, DQ numbers, GenBank) are indicated. An important inferred barrier is illustrated by the red line coinciding with the Rio Mira estuary. The presence of this barrier was supported by a clear increase in amplification failure (dashed arrow). Significant $F_{\mathrm{ST}}$ genetic distance across this barrier is illustrated for both mitochondrial fragments $(P<0.001)$. Triangles indicate mountainous areas (Serra de Monchique and Serra do Caldeirão). Corresponding regional locations are described in supplementary Table S1.

were used for genetic analysis. DNA was extracted following a standard Proteinase $\mathrm{K} /$ phenol-chloroform extraction protocol (Sambrook et al., 1989). We amplified fragments coding for a $385 \mathrm{bp}$ portion of cytochrome $b$ and a $562 \mathrm{bp}$ portion of $16 \mathrm{~S}$ rRNA mitochondrial genes using MVZ15 and cyt $b 2$ (Moritz et al., 1992; Kocher et al., 1989) primers for cytochrome $b$ and 16Sar and 16Sbr (Palumbi et al., 2002) primers for 16S rRNA with annealing $\left(\mathrm{T}_{\mathrm{a}}\right)$ at $50.5^{\circ} \mathrm{C}$ and $48^{\circ} \mathrm{C}$, respectively. Both primer pairs were known to successfully amplify Pleurodeles spp. mitochondrial sequences (Carranza and Arnold, 2004; Carranza and Amat, 2005). PCR amplifications were performed in a $25-\mu 1$ reaction volume containing approximately $20 \mathrm{ng}$ DNA, $0.5 \mu \mathrm{M}$ of each primer, $2.0 \mathrm{mM} \mathrm{MgCl}_{2}$, 5 X GoTag Flexi buffer (Promega), $0.2 \mathrm{mM}$ of each dNTP and 1.0 U GoTag DNA Polymerase (Promega). The PCR program held 38 cycles with $95^{\circ} \mathrm{C}$ for 40 sec, primer specific annealing temperature for $60 \mathrm{sec}$, and $72^{\circ} \mathrm{C}$ for $60 \mathrm{sec}$. For all PCR reactions, we started with a denaturation step of $94^{\circ} \mathrm{C}$ for $5 \mathrm{~min}$ and the last cycle was followed by a $7 \mathrm{~min}$ extension at $72^{\circ} \mathrm{C}$.

Alignments of nucleotide sequences were constructed for both mitochondrial fragments with Geneious 4.8.5 (Drummond et al., 2009), including published sequences from individuals from Portugal and Spain (cytochrome b: AY222515-16, 25, 31-32; 16S rRNA: DQ092261-62; locations, Fig. 1). Statistical parsimony networks were created in TCS (Clement et al., 2000), using a 95\% statistical confidence limit for the maximum number of nucleotide substitutions between two haplotypes. Nucleotide/ haplotype diversity and DNA divergence were estimated using DNASP 4.1 (Rozas, 2009). For subsequent phylogenetic analyses, the sequences of an outgroup species, Pleurodeles poireti, were included in the alignment (cytochrome $b$ AY222507-08; 16S 
rRNA DQ092263, GenBank); this is a sister species of $P$. waltl, from North Africa.

Phylogenetic relationships were estimated using NeighborJoining (NJ) in GeNEIOUs version 4.8.5 (Drummond et al., 2009), Maximum Likelihood (ML, PHYML v2.4.4; Guindon and Gascuel, 2003), and Bayesian inference (BI, MRBAYES version 3.1; Huelsenbeck and Ronquist, 2001; Ronquist and Huelsenbeck, 2003). For NJ, default settings with the Jukes-Cantor or HKY substitution models were used to test consistency of results. The Akaike Information Criterion (AIC) implemented in MrModeltest version 2 (Nylander, 2004) revealed that the best fit models of sequence evolution for cytochrome $b$ and $16 \mathrm{~S}$ rRNA were GTR + I and HKY + I, respectively. This difference precluded combining the two mtDNA sequences for subsequent analyses. For ML, we applied the estimated transition/ transversion ratio and proportions of invariable sites at 0.572 (cytochrome $b$ ) and 0.877 (16S rRNA). In the Bayesian analyses, default settings were used for the prior distributions. We ran four Metropolis coupled Monte Carlo Markov chains (MC3) for 1,100,000 generations, sampling every 200 generations. Five hundred trees were discarded as burn-in. Robustness of the inferred trees was evaluated by bootstrapping (1,000 replicates) and using Bayesian posterior probabilities.

To identify barriers in space, we used Monmonier's maximum differences algorithm (Monmonier, 1973) implemented in BARRIER v2.2 software (Manni et al., 2004). The computation based on both sequence data sets was performed by looking for maximum genetic distance values between neighbor sampling sites. The importance of a boundary or barrier was indicated by its bootstrap score, as support for a higher than expected genetic distance relative to geographic distance (indicated in the results by the proportional thickness of the barrier-line). We tested the significance of $F_{\mathrm{ST}}$ across a dominant barrier with 10,000 random permutations.

Multilocus genotype data was based on 14 microsatellite loci, and PCR conditions were as described by van de Vliet et al. (2009c). All PCR reactions were performed with a GeneAmp 2700 thermocycler (PE Applied Biosystems), and fragment sizes were determined on an ABI prism 3130XL capillary sequencer. Micro-Checker 2.2.3 (Van Oosterhout et al., 2004) was applied to check microsatellite data for scoring errors and putative null alleles. Numbers of used sites and individuals are indicated in Table S1. Amplification failure per locus was determined as the number of individuals showing consistent failure (no identifiable or ambiguous PCR products after two PCR genotyping efforts).

To verify whether the mitochondrial patterns observed (see below) were coincident at nuclear loci, fine-scale differentiation patterns across the Rio Mira estuary were further analyzed using microsatellite genotypes for individuals from the two regions, located on each side of the estuary: seven ponds to the south (see Table S1; Alm, $N=100$ ) and eight ponds to the north (see Table S1; VNM, $N=41$ ). Patterns of (1) recent (asymmetric) dispersal based on allele frequency differences and (2) unique alleles per locus across inferred barriers were detected by using Geneclass 2.0 (Piry et al., 2004) and standArich (Alberto, 2006), respectively, only using microsatellite loci with low to modest amount of amplification failure $(<10 \%)$ and no sign of nullalleles. Furthermore, relationships among individuals and potential existence of genetic subdivision were visualized over multilocus genotypes (for all loci as for loci showing no failure) using factorial correspondence analysis (FCA, GENETIX 4.05, Belkhir et al., 2004) and a Bayesian clustering approach implemented in the software STRUCTURE 2.3.1 (Pritchard et al., 2000). In the latter method, genetic units are defined by minimizing linkage disequilibrium (LD) and departures from Hardy-Weinberg equilibrium (HWE). Five independent runs with 100,000 iterations and a burn-in of 25,000 were performed assuming admixture, correlated allele frequencies, and without a priori spatial information of individuals. After defining the appropriate value of lambda, the best number of genetic units (K) was determined by comparing the log-likelihood considering $\mathrm{K}$ between one to $\mathrm{K}=$ number of different sampling sites.

\section{RESULTS}

Partial mitochondrial cytochrome $b$ and 16S rRNA sequences were obtained for 131 and 152 individuals, respectively (for details of number of individuals per breeding site and number of breeding sites per location, see Table S1). Ten (cytochrome $b$ ) and 11 (16S rRNA) different haplotypes $\left(\mathrm{N}_{\mathrm{h}}\right)$ were found for the total study area (GenBank accession numbers: JF803783JF803803) and were defined by 10 and nine variable positions (segregating sites), respectively. Observed nucleotide diversity $(\pi)$ was relatively low, but haplotype diversity $(\mathrm{H})$ was moderate to high (cytochrome $b, \pi=0.0056, \mathrm{H}=0.815 ; 16 \mathrm{~S}$ rRNA , $\pi=0.0034, \mathrm{H}=0.792)$.

The parsimony network of mtDNA haplotypes revealed that regions located in southwest Portugal contained the ancestral haplotype (Fig. 2). The network for cytochrome $b$ (Fig. 2A) supported the presence of two distinct groups with an average of 3.5 nucleotide differences $\left(D_{a}=0.0067\right)$. The first group contained locations from south-southwest Portugal, and the second group included the locations north-northeast of the Rio Mira. For 16S rRNA (Fig. 2B), this pattern was also present but slightly less marked (average of 3.3 nucleotide differences, $\mathrm{D}_{\mathrm{a}}=$ 0.0045). In addition, both markers showed the presence of the same few individuals north of the river but containing the southern haplotype.

Phylogenetic analyses based on cytochrome $b$ sequence data using Neighbor-Joining, Maximum Likelihood and Bayesian inference gave concordant results (Fig. 3). Analysis based on $16 \mathrm{~S}$ rRNA groups were not well supported (Fig. S1, which is available at: http://dx.doi.org/10.1670/12-181s1). Individuals sampled north-northeast of the Rio Mira clustered with published sequences of individuals from central-west Spain, forming a group (here called Clade 1, see also Fig. 1) that has no statistical support as a single clade but is nevertheless distinct from another well-supported clade (here called Clade 3). Clade 3 was based on clustered sequences from south-southwest Portugal. Clade 2 was most divergent, containing published sequences from southeast Spain (Carranza and Arnold, 2004). Divergence between Clades 1 and 3 in southwest Portugal was concordant with the presence of the Rio Mira estuary as a barrier, and unfavorable mountainous areas like Serra de Monchique and Serra do Caldeiräo. Dominant genetic discontinuities identified using BARRIER v2.2 also confirmed the Rio Mira as an important geographic barrier (Fig. 1). There was a highly significant $F_{\mathrm{ST}}$-value $(P<0.001)$ between ponds sampled in the two margins of the Rio Mira (Alm and VNM; Fig. 1).

The microsatellite data set used to compare individuals from both sides of the Rio Mira showed low amplification failure across all 14 loci for populations south of the Rio Mira (0-1\%, Table 1), but amplification failure increased significantly for individuals from sites north of this river (13.6\%, Table 1). In addition, eight loci showed evidence of null alleles in this 
A

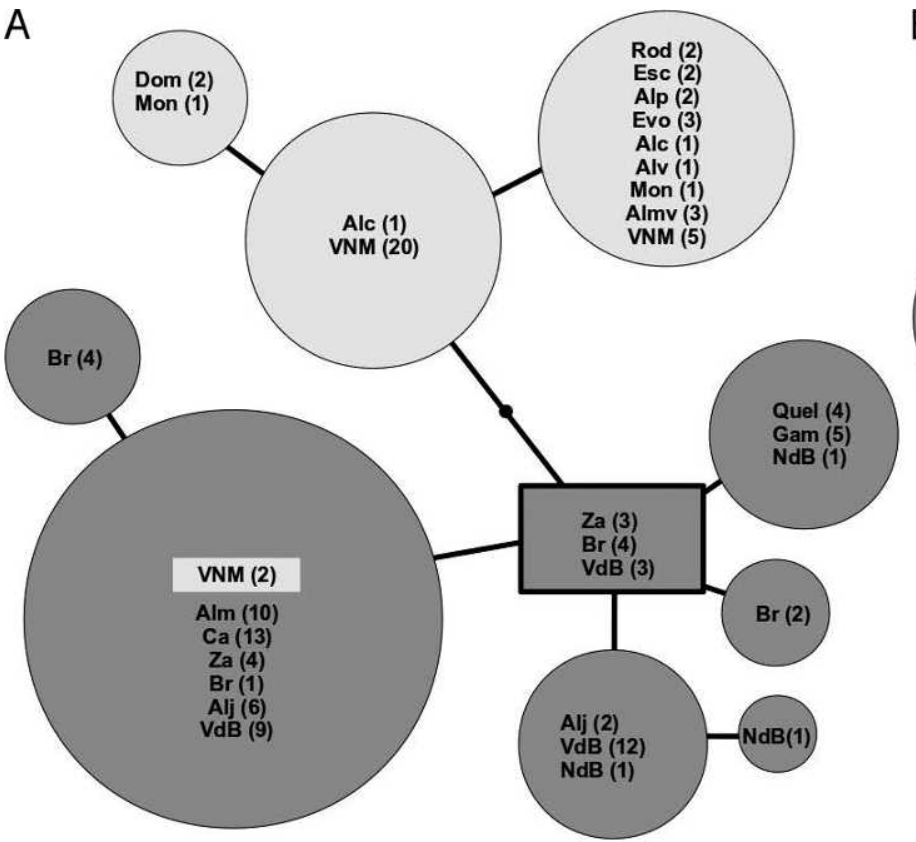

B

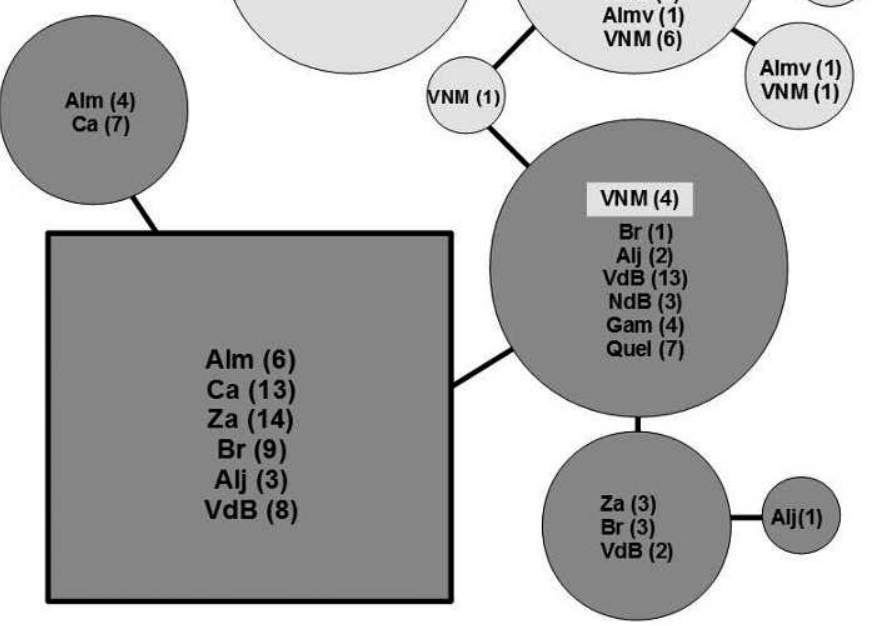

FIG. 2. Haplotype networks constructed using statistical parsimony (95\% statistical confidence limit). (A) cytochrome $b$; (B) $16 \mathrm{~S}$ rRNA. The relative sizes of the circles reflect the frequencies of the different haplotypes. Squares indicate the ancestral haplotype. Number of sequenced individuals (between brackets), for each location, are indicated. Lines between circles represent single mutational steps; black dots represent hypothetical haplotype which connect observed haplotypes. Haplogroups found for regions south or north-northeast of the dominant barrier "Rio Mira estuary" are indicated as dark and light grey, respectively.

region north of Rio Mira (i.e., VNM). Because of this, subsequent analyses based on microsatellite markers were restricted to the six loci that showed neither high amplification failure nor null alleles in the northern region (VNM). However, the geographic segregation of reduced amplification success to the region north of the Rio Mira was an interesting result in itself.
Geneclass 2.0 showed no support for any recent dispersal of first generation migrants between Alm and VNM, and only occasional dispersal was observed within each region (2 of 41 individuals for VNM, and 5 of 100 individuals for Alm). The pattern of mitochondrial differentiation between the regions across the Rio Mira estuary was well supported by FCA and STRUCTURE when using all 14 microsatellite loci (Fig. 4 A,B;

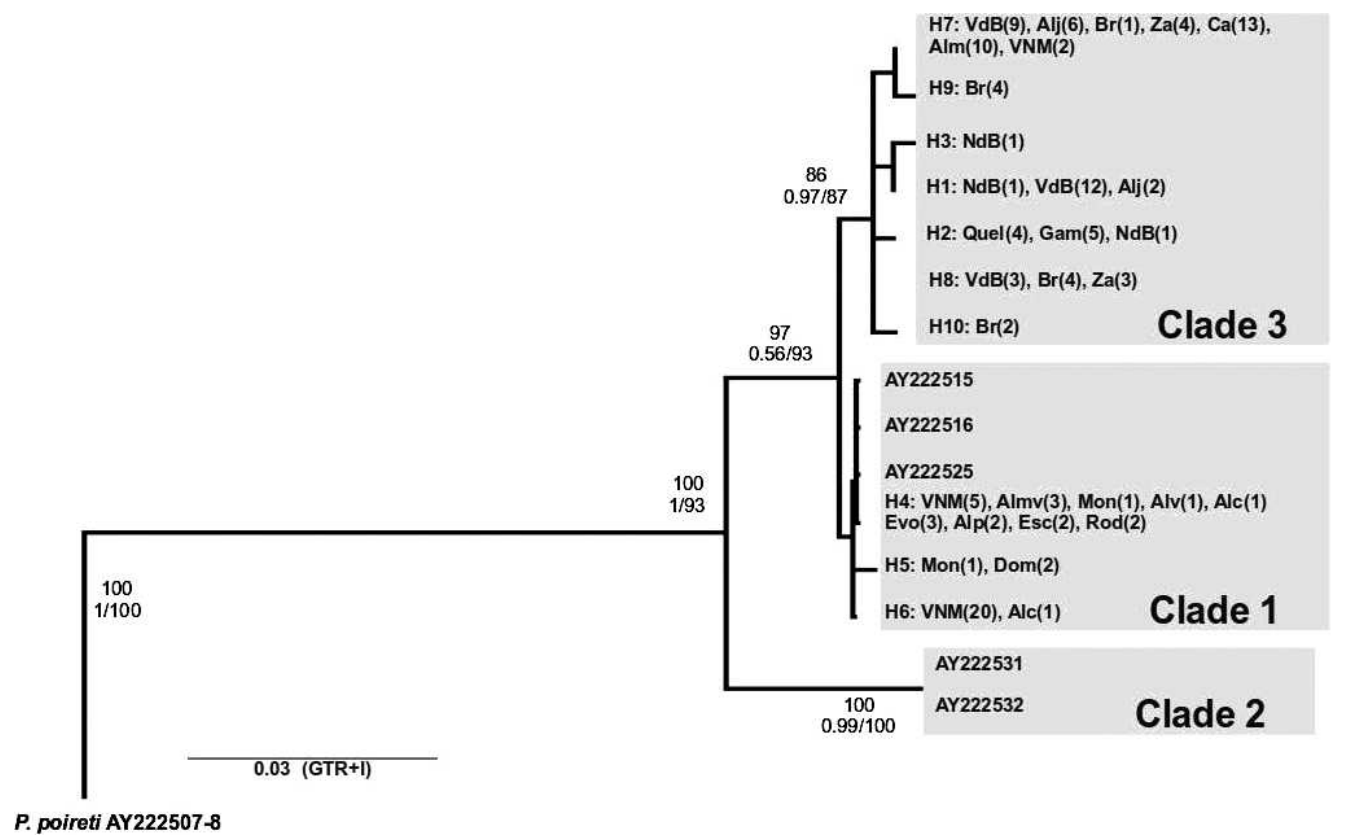

FIG. 3. Phylogenetic tree of Pleurodeles waltl for individuals from the Iberian Peninsula inferred from mitochondrial cytochrome $b$ sequences. Numbers in the major nodes correspond to NJ bootstrap proportions (above branches) and below branches BI (Bayesian inference) posterior probabilities and maximum likelihood, respectively. AY-accession numbers (GenBank) for published sequences and haplogroup numbers (1-10) corresponding to accession numbers JF803794-JF803803 (GenBank) are indicated, including ID-locations and within brackets number of sequenced individuals. 
TABLE 1. Percentage of amplification failure and positive tests of null alleles per locus per region. Boldface indicates positive tests of null-alleles.

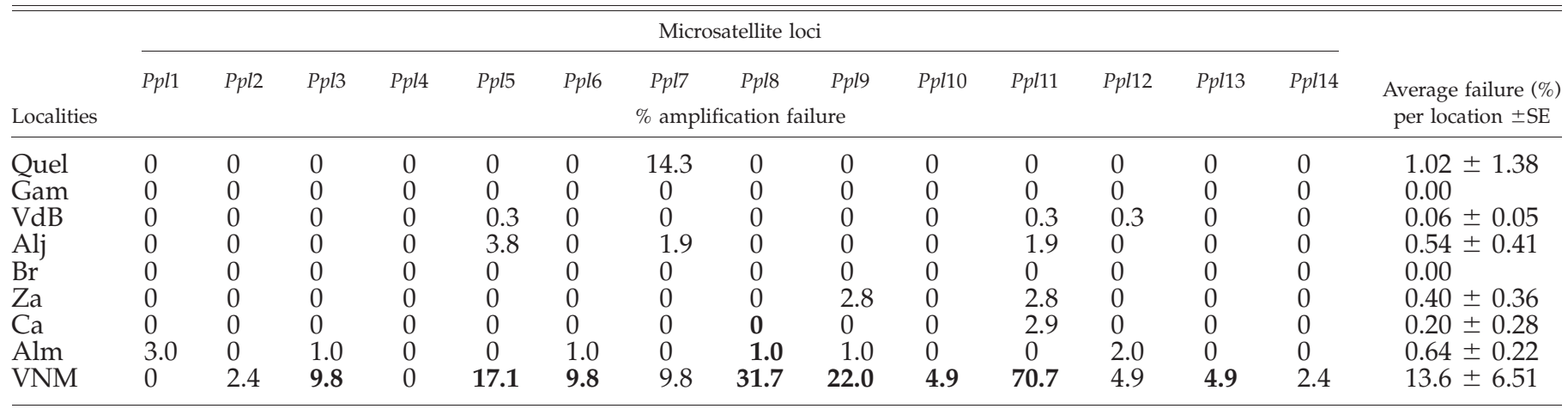

Fig. S3, which is available in the online supplementary file). STRUCTURE inferred three genetic units, namely VNM and two clusters in Alm, separating one more distant pond (south of Rio Mira in Fig. 1; solid squares in Fig. 4 A,B, and blue bars in supplementary Fig. S3) from all six others that are spatially clustered together further south. Within the northern cluster of individuals, the FCA analysis showed separation of those that were collected north of the estuary but had the southern mitochondrial haplotypes. However, their nuclear genotypes appeared distinct to some extent from those in both northern and southern ponds (see also unique alleles below). Results in STRUCTURE based on just the six markers revealed only one genetic unit $(K=1)$, and individuals formed a continuum rather than clearly discrete groups in the FCA (Fig. 4B), a likely result of the lower resolution obtained with a smaller number of loci. When comparing the two regions south $(N=100)$ and north $(N$ $=41$ ) of the Rio Mira, using only the six loci with no failure, we found 26 and 16 unique alleles, respectively. Nine of the latter 16 were still unique when comparing VNM to all regions south of the Rio Mira until VdB in the Algarve. The few individuals characterized by the southern haplotype Clade 3 in VNM had 4 of these 9 rare alleles (blue dots in Fig. S2, which is available in the online supplementary file), which were not found across all southern populations sampled southward up to the Algarve.

\section{DisCUSSION}

The comparison between mitochondrial and nuclear markers allowed inferences as to the causes of spatial distribution of genetic diversity in $P$. waltl in southwest Portugal. Sequence differentiation and spatial variation in microsatellite amplification success both supported the existence of divergent lineages in south-southwest Portugal and contributed to the identification of possible barriers to dispersal responsible for maintaining genetic differentiation.
A

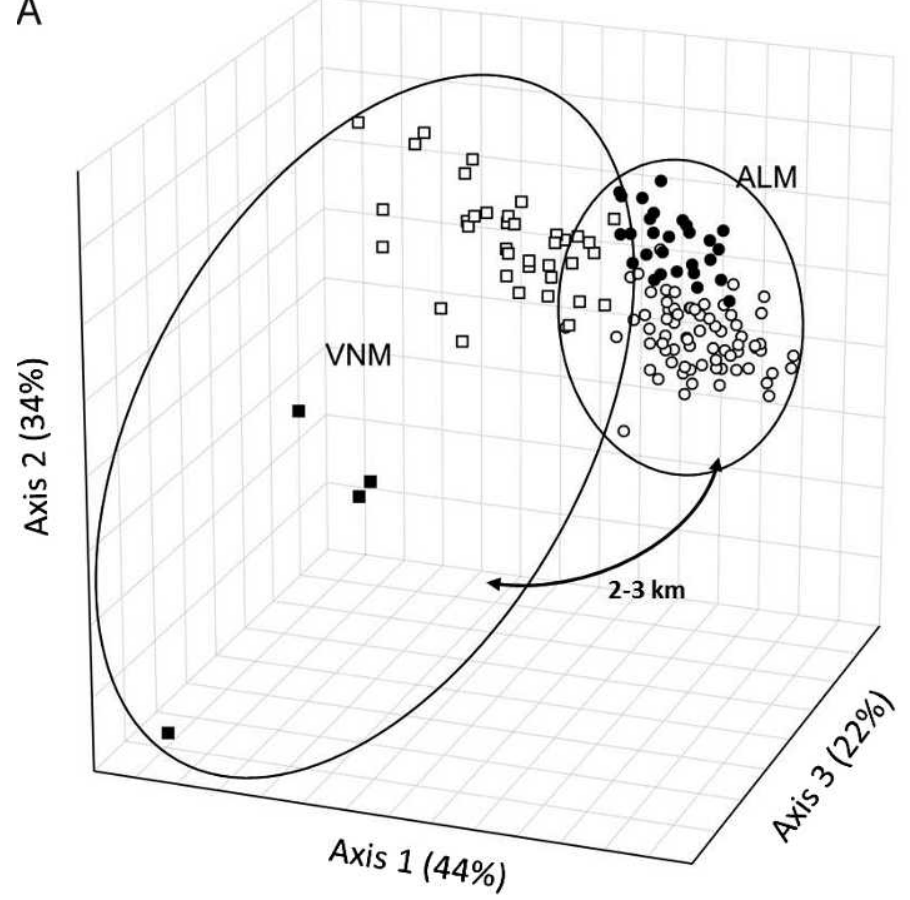

B

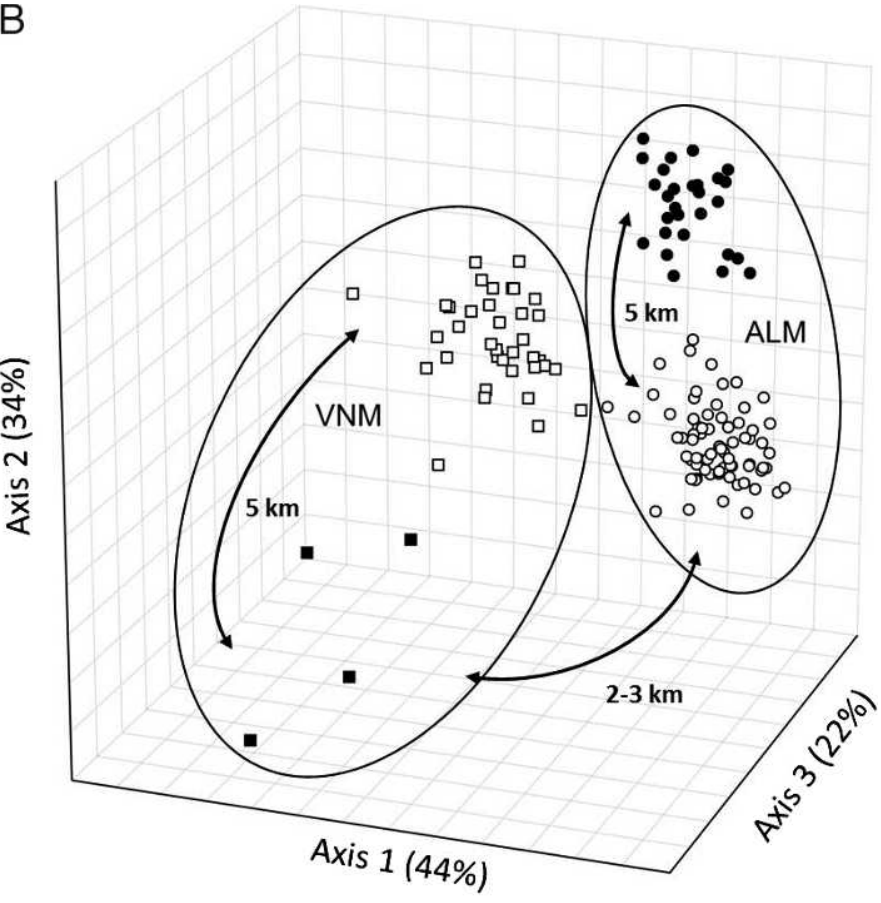

FIG. 4. Factorial Correspondence Analysis (FCA) showing differentiation of individuals across the Rio Mira estuary. Analyses were based on either 14 loci (A) or the six loci showing neither amplification failure nor null alleles (B). Different symbols for individuals indicate the three inferred clusters based on STRUCTURE results using 14 loci (supplementary Fig. S3). Alm: two clusters (open circles, 72 individuals//six ponds; solid circles, 28 individuals//1 pond). VNM: one cluster (squares, 41 individuals//eight sites), including individuals with the northern mithocondrial haplotype (open squares), and individuals with the southern mithocondrial haplotype and unique alleles (solid squares) (supplementary Fig. S2). 
We found no evidence of any recent dispersal of firstgeneration migrants between ponds in the northern (VNM) and the southern margin (Alm) of Rio Mira, suggesting that the river (and mountainous areas further upstream) may act as an important contemporary barrier. Rivers and mountain ridges acting as barriers to amphibian gene flow have been revealed in several studies (reviewed in Emel and Storfer, 2012). In VNM, we detected a few individuals with the southern mitochondrial haplotype, which contained rare microsatellite alleles and were separated in FCA from other individuals collected in the north. This separation was not detected by STRUCTURE, probably because methods based on minimization of HW disequilibrium and LD are less sensitive than allele frequency-based analysis such as FCA. Remarkably, the unique alleles in these specific individuals were not found across the southern populations, suggesting the occurrence of migration from other populations with the southern mitochondrial haplotypes but outside our study area (coastal plateau from Almograve to Vila do Bispo). Unfortunately, our data were insufficient to complete the picture of (ancestral) dispersal patterns, because we did not sample all possible breeding sites, and the resolution of analyses based on the six loci without amplification problems was low.

Divergent mitochondrial lineages were also observed in central-southwestern Portugal for another urodele species Lissotriton boscai (Martínez-Solano et al., 2006), probably reflecting restrictions to gene flow and isolation by distance (Martínez-Solano et al., 2006). Comparable phylogeographic processes may have affected $P$. waltl, with a natural barrier created by a river in combination with isolation by distance possibly explaining the marked spatial pattern across the Rio Mira. However, marked divergence between lineages across the Rio Mira was not found in two anurans, Pelodytes sp. and Pelobates cultripes, also breeding in temporary ponds (van de Vliet et al., 2012; van de Vliet, unpubl), suggesting that the river may not be an important barrier for all amphibian species. Also, low levels of admixture between adjacent phylogenetic lineages were observed for a cobreeding aquatic invertebrate Triops mauritanicus (Korn et al., 2010), which has resistant eggs that may be dispersed by birds and, thus, should not be affected by relatively narrow barriers such as rivers. For T. mauritanicus, high genetic sub-structuring was hypothesized to be a consequence of range expansions and contractions, caused by regular and strong fluctuations between forest and steppe vegetation associated with climatic oscillations (Korn et al., 2010). Specialization of this species in relatively rare temporary pond habitats could have magnified the effect of barriers created by mountain ranges or large rivers, limiting post-glacial recolonizations and range expansion, thereby contributing to maintain geographically restricted populations with low gene flow between divergent lineages (Korn et al., 2010). It is also possible that phylogenetic lineages for $P$. waltl are related to the emergence of the Serra do Caldeirão mountains during the Lower Pliocene, which appeared to have shaped congruent geographic patterns of divergence for different taxa in the study area (e.g., Gonçalves et al., 2009).

In past glacial periods, the isolation of $P$. waltl populations by mountain chains, rivers, and sea straits was probably higher than today, because of constraints such as as thermoregulatory needs, habitat availability, and low salinity tolerance. However, Clade I occupies a large geographical area, and the samples were relatively homogeneous genetically (see also Carranza and Arnold, 2004); a spatial pattern also found for the other cobreeding species mentioned above. This pattern could result from population persistence in a single refugium followed by a recent and rapid range expansion. Although levels of divergence between lineages were low compared to recognized Pelodytes sp. and T. mauritanicus lineages (Korn et al., 2010; van de Vliet et al., 2012), low levels of admixture, and increased amplification failure across a river barrier are both signals of genetic divergence in a relatively small area. Low divergence can also be explained by a slow rate of mitochondrial gene evolution as observed in other salamandrids (Carranza and Arnold, 2004).

In terms of conservation, it is noteworthy that divergence of $P$. waltl populations to the south of the Rio Mira matches that observed in other amphibians (van de Vliet et al., 2012) and aquatic invertebrates (Korn et al., 2010) inhabiting temporary ponds in southwest Portugal. These results emphasize the presence of unique biodiversity patterns, reinforcing previous calls to promote temporary pond conservation in this region (Beja and Alcazar, 2003; Cancela da Fonseca et al., 2008). Although the region is partly included in a natural park (Parque Natural do Sudoeste Alentejano e Costa Vicentina) and within a site protected under the European Directive 92/43/EEC, temporary ponds have been rapidly disappearing because of the conversion from traditional to intensive farming regimes (Beja and Alcazar, 2003). Given this decline in temporary ponds, the conservation status of the divergent lineages of $P$. waltl and that of other species co-occurring in such habitats should be established. In addition, more comparative studies, including both morphological and fine-scale genetic data (taking into account the consequences of increased amplification failure), are needed to clarify the phylogenetic relationships among populations of this newt in southwest Portugal.

Acknowledgments.-This work was supported by Fundação para a Ciência e Tecnologia (Portugal) with support from FEDER, through research project PTDC/BIA-BDE/68730/2006, and SFRH/BD/24064/2005 PhD grant (FCT, ESF). All samples were collected with the appropriate licenses issued by Instituto de Conservação da Natureza in Portugal.

\section{Literature Cited}

AlberTo, F. 2006. StandArich v1.0: an R package to estimate population allelic richness using standardized sample size [Internet]. Available from: http://www.ccmar.ualg.pt/maree/software.php?soft=sarich. Accessed WebCite: http://www.webcitation.org/6FvpviTep on 16 April 2013.

Almada, V., and C. Sousa-Santos. 2010. Comparisons of the genetic structure of Squalius populations (Teleostei, Cyprinidae) from rivers with contrasting histories, drainage areas and climatic conditions based on two molecular markers. Molecular Phylogenetics and Evolution 57:924-931.

Avise, J. C. 2000. Phylogeography: The History and Formation of Species. Harvard University Press, Cambridge, MA.

Beja, P., and R. Alcazar. 2003. Conservation of Mediterranean temporary ponds under agricultural intensification: an evaluation using amphibians. Biological Conservation 114:317-326.

Belkhir, K., P. Borsa, L. Chikhi, N. Raufaste, and F. Bonhomme. 2004. GENETIX 4.05, logiciel sous Windows TM pour la génétique des populations [Internet]. Available from: http://kimura.univ-montp2. fr/genetix/. Accessed WebCite http://www.webcitation.org/ 6FvtV7ZeL on 16 April 2013.

Blondel, J., J. Aronson, J. Y. Bodiou, and G. Boeuf. 2010. The Mediterranean Basin Biological Diversity in Space and Time. Oxford University Press, Oxford.

Cancela da Fonseca, L., M. Cristo, M. Machado, J. Sala, J. Reis, R. Alcazar, AND P. BejA. 2008. Mediterranean temporary ponds in 
southern Portugal: key faunal groups as management tools? PanAmerican Journal of Aquatic Sciences 3:304-320.

CARRANZA, S., AND F. AMAT. 2005. Taxonomy, biogeography and evolution of Euproctus (Amphibia: Salamandridae), with the resurrection of the genus Calotriton and the description of a new endemic species from the Iberian Peninsula. Zoological Journal of the Linnean Society of London 145:555-582.

Carranza, S., AND E. N. ARnold. 2004. History of west Mediterranean newts, Pleurodeles (Amphibia: Salamandridae), inferred from old and recent DNA sequences. Systematics and Biodiversity 1:327-337.

Clement, M., D. Posada, and K. Cranddall. 2000. TCS: a computer program to estimate gene genealogies. Molecular Ecology 9:16571660 .

Comes, H. P., AND R. J. АввотT. 1998. The relative importance of historical events and gene flow on the population structure of a Mediterranean Ragwort, Senecio gallicus (Asteraceae). Evolution 52:355-367.

Drummond, A. J., B. Ashton, M. Cheung, J. Heled, M. Kearse, R. Moir, S. Stones-Havas, T. Thierer, and A. Wilson. 2009. Geneious v4.8.5 [Internet]. Available from http://www.geneious.com. Accessed WebCite http://www.webcitation.org/6FvuM0xmw on 17 April 2013.

Emel, S. L., AND A. Storfer. 2012. A decade of amphibian population genetic studies: synthesis and recommendations. Conservation Genetics 6:1685-1689.

Gasc, J. P. 1997. Atlas of Amphibians and Reptiles in Europe. Societas Europaea Herpetologica, Bonn, Germany.

GómeZ, A., AND D. H. LunT. 2007. Refugia within refugia: patterns of phylogeographic concordance in the Iberian Peninsula. In S. Weiss and N. Ferrand (eds.), Phylogeography in Southern European Refugia: Evolutionary Perspectives on the Origins and Conservation of European Biodiversity, pp. 155-182. Springer, Dordrecht, the Netherlands.

Gonçalves, H., I. Martínez-Solano, R. Pereira, B. Carvalho, M. GarcíaPARIS, AND N. FERRAND. 2009. High levels of population subdivision in a morphologically conserved Mediterranean toad (Alytes cisternasii) result from recent, multiple refugia: evidence from mtDNA, microsatellites and nuclear genealogies. Molecular Ecology 18: 1543-5160.

GUICKING, D., U. Joger, AND M. Wink. 2002. Molecular phylogeography of the Viperine Snake (Natrix maura) and the Dice Snake (Natrix tessellata): first results. Biota 3/1-2:47-57.

GUINDON, S., AND O. GASCUEL. 2003. A simple, fast and accurate algorithm to estimate large phylogenies by maximum likelihood. Systematic Biology 52:696-704.

Hendrix, R., J. S. Hauswaldt, M. Veith, and S. Steinfartz. 2010. Strong correlation between cross-amplification success and genetic distance across all members of "true salamanders" (Amphibia: Salamandridae) revealed by Salamandra salamandra-specific microsatellite loci. Molecular Ecology Resources 10:1038-1047.

HewitT, G. 2000. The genetic legacy of the Quaternary ice ages. Nature 405:907-913

2004. Genetic consequences of the climatic oscillations in the Quaternary. Philosophical Transactions of the Royal Society of London B Biological Sciences 39:183-195.

HuELSENBECK, J. P., AND F. RoNQUIST. 2001. MrBayes: Bayesian inference of phylogeny. Bioinformatics 17:754-755.

Kocher, T. D., W. K. Thomas, A. Meyer, S. V. Edwards, S. Paabo, F. X. Vilablanca, and A. C. Wilson. 1989. Dynamics of mitochondrial DNA evolution in animals. Proceedings of the National Academy of Science of the United States of America 86:6196-6200.

Korn, M., A. J. Green, M. Machado, J. Garcia-de-Lomas, M. Cristo, L. Cancela da Fonseca, D. Frisch, J. L. Pérez-Bote, and A. K. HundSDOERFER. 2010. Phylogeny, molecular ecology and taxonomy of southern Iberian lineages of Triops mauritanicus (Crustacea: Notostraca). Organisms Diversity and Evolution 10:409-440.

Loureiro, A., N. Ferrand, M. A. Carretero, and O. Paulo. 2010. Atlas dos Anfíbios e Répteis de Portugal. Esfera do Caos, Lisbon, Portugal.

Manni, F., E. Guérard, and A. Heyer. 2004. Geographic patterns of (genetic, morphologic, linguistic) variation: how barriers can be detected by "Monmonier's algorithm." Human Biology 76(2):173190.
Martínez-Solano, I., J. Teixeira, D. Buckley, and M. García-Paris. 2006. Mitochondrial DNA phylogeography of Lissotriton boscai (Caudata, Salamandridae): evidence for old, multiple refugia in an Iberian endemic. Molecular Ecology 15:3375-3388.

Miraldo, A., G. M. Hewitt, O. S. Paulo, and B. C. Emerson. 2011. Phylogeography and demographic history of Lacerta lepida in the Iberian Peninsula: multiple refugia, range expansions and secondary contact zones. BMC Evolutionary Biology 11:170. Available from: http:/ / www.biomedcentral.com/1471-2148/11/170.

MONMONIER, M. 1973. Maximum-difference barriers: an alternative numerical regionalization method. Geographical Analysis 3:245-261.

Nylander, J. A. A. 2004. MrModeltest v2 [Internet]. Available from: http://www.abc.se/ nylander/mrmodeltest2/mrmodeltest2.html. Accessed WebCite http://www.webcitation.org/6FvuoNatZ on 17 April 2013.

Palumbi, S., A. Martin, S. Romano, W.O. McMillan, L. Stice, and G. GRABOWSKI. 2002. The Simple Fool's Guide to PCR, version 2 [Internet]. Available from: http:// palumbi.stanford.edu/SimpleFoolsMaster.pdf. Accessed WebCite http://www.webcitation.org/6Fvvf6MqB on 17 April 2013.

Piri, S., A. Alapetite, J. M. Cornuet, D. Paetkeu, L. Baudouin, and A. Estoup. 2004. GeneClass2: a software for genetic assignment and first generation migrants detection. Journal of Heredity 95:536-539.

Pritchard, J. K., M. Stephens, and P. Donnelly. 2000. Inference of population structure using multilocus genotype data. Genetics 155: 945-959.

Ronquist, F., And J. P. Huelsenbeck. 2003. MrBayes 3: Bayesian phylogenetic inference under mixed models. Bioinformatics 19: 1572-1574.

RozAS, J. 2009. DNA sequence polymorphism analysis using DnaSP. In D. Posada (ed.), Bioinformatics for DNA Sequence Analysis. Methods in Molecular Biology Series, Volume 537. pp. 337-350. Humana Press, New York.

Sснмітт, T. 2007. Molecular biogeography of Europe: Pleistocene cycles and postglacial trends. Frontiers in Zoology 4:11. Available from: http:/ / www.frontiersinzoology.com/content/4/1/11.

Smith, M. A., AND D. M. GREEN. 2005. Dispersal and the metapopulation paradigm in amphibian ecology and conservation: are all amphibian populations metapopulations? Ecography 28:110-128.

Steinfartz, S., M. Veith, and D. Tautz. 2000. Mitochondrial sequence analysis of Salamandra taxa suggests old splits of major lineages and postglacial recolonizations of Central Europe from distinct source populations of Salamandra salamandra. Molecular Ecology 9:397-410.

Stoate, C., A. Báldi, P. Beja, N. D. Boatman, I. Herzon, A. van Doorn, G. R. DE SNOO, L. Rakosy, and C. Ramwell. 2009. Ecological impacts of early 21st century agricultural change in Europe-a review. Journal of Environmental Management 91:22-46.

van de Vliet, M. S., O. E. Diekmann, E. T. A. Serrão, and P. Beja. 2009a. Highly polymorphic microsatellite loci for the Parsley Frog (Pelodytes punctatus): characterization and testing for cross-species amplification. Conservation Genetics 10:665-668.

- 2009b. Isolation of highly polymorphic microsatellite loci for a species with a large genome size: Sharp-Ribbed Salamander (Pleurodeles walt). Molecular Ecology Resources 9:425-428.

- 2009c. Development and characterization of highly polymorphic microsatellite loci for the Western Spadefoot Toad, Pelobates cultripes. Conservation Genetics 10:993-996.

van de Vliet, M. S., T. J. C. Beebee, and O. E. Diekmann. 2012. Genetic evidence for a distinct Pelodytes lineage in southwest Portugal: implications for the use of pre-developed microsatellite markers. Conservation Genetics 13:605-611.

Van Oosterhout, C., W. F. Hutchinson, D. P. M. Wills, and P. Shipley. 2004. Micro-Checker: software for identifying and correcting genotyping errors in microsatellite data. Molecular Ecology Notes 4:535-538.

ZeISSET, I., AND T. J. C. BEEBEE. 2008. Amphibian phylogeography: a model for understanding historical aspects of species distributions. Heredity $101: 109-119$.

Accepted: 4 March 2013. 